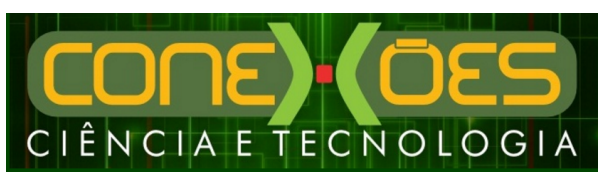

\title{
O ENSINO DE MICROBIOLOGIA NAS ESCOLAS PÚBLICAS DE ENSINO FUNDAMENTAL DO MUNICÍPIO DE JAGUARIBE, CEARÁ
}

\author{
Chayenne Alves de $\mathrm{SA}^{1}$, Kylvia Rocha de Castro e Silva ${ }^{2,3}$, Valdineia Soares Freitas ${ }^{2,4}$ \\ ${ }^{1}$ Universidade Federal do Ceará (UFC) \\ ${ }^{2}$ Instituto Federal de Educação, Ciência e Tecnologia do Ceará (IFCE) \\ ${ }^{3}$ Campus de Fortaleza \\ ${ }^{4}$ Campus de Paracuru \\ <chayennebio@gmail.com>,<kylviarocha@ifce.edu.br>.<valdineiasoares@ifce.edu.br>
}

DOI: $10.21439 /$ conexoes.v12i1.1380

\begin{abstract}
Resumo. A Microbiologia é um ramo da Biologia que está intimamente relacionada à saúde humana e ao bom funcionamento do meio ambiente. O presente trabalho foi desenvolvido com alunos e professores de quatro turmas do $7^{\circ}$ ano do Ensino Fundamental, em quatro escolas públicas de Educação Básica da cidade de Jaguaribe/CE, e objetivou analisar como os temas relacionados à Microbiologia têm sido ensinados. Foram feitas observações em sala de aula e aplicação de questionário a alunos e professores. As observações e os dados coletados nos permitiram inferir que, embora haja uma avaliação satisfatória do grupo (professores e alunos) sobre como os temas relacionados à Microbiologia vem sendo ensinados, existe por parte deles o anseio de que sejam realizadas melhorias no ensino de Microbiologia. Esses resultados confirmam a necessidade de aproximação entre os conteúdos ensinados em Microbiologia e as diferentes estratégias de ensino-aprendizagem, tais como a realização de atividades práticas e lúdicas, tendo em vista que essas possibilitarão uma dinamização das aulas, fomentando nos alunos o desejo de atuarem juntamente com o professor, como agentes na construção do conhecimento.
\end{abstract}

Palavras-chaves: Ensino de Ciências. Ensino Fundamental. Microbiologia.

\section{THE MICROBIOLOGY TEACHING IN ELEMENTARY EDUCATION PUBLIC SCHOOLS OF THE CITY OF JAGUARIBE, CEARÁ}

\begin{abstract}
Microbiology is a branch of biology that is closely related to human health and the proper functioning of the environment. This work was developed with students and teachers from four classes of 7 th grade of elementary school in four public schools in the basic education system in the city Jaguaribe/CE, and aimed to analyze how issues related to Microbiology have been taught. Observations were made in the classroom and questionnaire to students and teachers. The observations and data collected allowed us to infer that, although there is a satisfactory assessment of the group on issues related to Microbiology is being taught there from them the desire that improvements are made in teaching Microbiology. These results confirm the need to approximate the Microbiology contents and the different teaching-learning strategies, such as the practical accomplishment and playful activities, since these will enable a dynamization of the classes, encouraging in the students to act together with the teacher, as agents in the knowledge construction.
\end{abstract}

Keywords: Science Education. Elementary Education. Microbiology. 


\section{INTRODUÇÃO}

A Biologia como parte do processo de construção cidadã, pode ser uma disciplina muito relevante e significativa para os alunos, dependendo da maneira de como é abordada (KRASILCHIK, 2011). Apesar disso, o Ensino de Ciências praticado nas escolas, de modo geral, tem sido ministrado de maneira não contextualizada, pautado em aprendizados e problemas que não exigem a compreensão dos conceitos trabalhados (SANTOS, 2007). Na educação em Ciências e Biologia, a integração entre a teoria e a prática possui grande relevância para os processos de aprendizado. Nesse contexto, Krasilchik (2011), ressalta que qualquer curso deve incluir uma diversidade de modalidades didáticas, pois cada situação exige uma solução própria; além de que, a variação das atividades pode atrair e interessar os alunos, atendendo dessa maneira às diferenças individuais.

A Microbiologia compreende um grande e diverso grupo de organismos microscópicos (as bactérias, os fungos, os protozoários e as microalgas) bem como, inclui os vírus e os príons que são microscópicos e acelulares (TORTORA; FUNKE; CASE, 2017; SPOLIDORIO; DUQUE, 2013; BROOKS et al., 2014). Como uma Ciência biológica básica a Microbiologia abrange dois temas centrais: o entendimento dos processos básicos da vida, e a aplicação desse entendimento para benefício da humanidade (MADIGAN et al., 2016).

Cassanti et al. (2008) afirmam que, apesar de sua grande relevância, a Microbiologia tem sido negligenciada pelos professores e isso pode ser um reflexo da dificuldade do desenvolvimento de estratégias de ensinoaprendizagem que melhore a compreensão dos alunos; ademais, a falta de conexão entre a Microbiologia e o dia a dia do aluno torna essa disciplina muito abstrata, o que certamente, dificulta ainda mais a aprendizagem do educando (CASSANTI et al., 2008; ANTUNES; PILEGGI; PAZDA, 2012; KIMURA et al. 2013). Somando-se aos argumentos acima, os microorganismos, na maioria das vezes, são apresentados no currículo escolar como unicamente, agentes causadores de doenças, apesar de apenas $2 \%$ deles serem patogênicos para o homem (CASSANTI et al., 2008). Isso pode gerar certa confusão nos conceitos construídos pelos alunos ao realizarem seu primeiro contato com a Microbiologia no Ensino Fundamental.

Segundo Silva e Bastos (2012) e Kimura et al. (2013), o estudo da Microbiologia dentro do currículo de Ciências no Ensino Fundamental necessita de novas ideias para o desenvolvimento de seus conteúdos em sala de aula, bem como, maneiras que auxiliem o professor a estimular os alunos a conhecer os micro- organismos. É nesse contexto que se faz necessário um melhor entendimento de como estão sendo ministrados os conteúdos relacionados à Microbiologia na Educação Básica, a fim de que se possam propor alternativas de ensino para essa disciplina e sua realidade escolar. Assim, a escolha do presente tema justifica-se pela sua importância, bem como pela escassez de estudos abordando as estratégias de ensino-aprendizagem em Microbiologia na Educação Básica, especialmente no ensino fundamental. Dessa maneira, o presente trabalho teve como objetivo analisar como se dá o ensino dos temas relacionados à Microbiologia na rede pública de Educação Básica da cidade de Jaguaribe/CE, a fim de subsidiar os primeiros conhecimentos acerca desse tema no município em questão.

\section{METODOLOGIA}

O presente trabalho foi realizado em quatro escolas da rede pública de Educação Básica da zona urbana da cidade de Jaguaribe, Ceará, Brasil, no período de fevereiro a abril de 2015. O município está sob as coordenadas geográficas de $37^{\circ} 46$ ' 52'S e $4^{\circ} 50$ ' 02 '”, na microrregião do Médio Jaguaribe, no sudoeste do Estado do Ceará, a $310 \mathrm{Km}$ da capital (IPECE, 2007). Possui 34 escolas públicas municipais de ensino fundamental, sendo quatro dessas localizadas em sua zona urbana.

Em um primeiro encontro com os docentes e discentes selecionados para participar da pesquisa, foram fornecidas informações sobre os objetivos, os procedimentos, os riscos e os benefícios do presente estudo. Aos interessados em participar do estudo foi apresentado o Termo de Consentimento Livre e Esclarecido (anexo 1), que foi assinado pelos professores ou pelos responsáveis dos discentes menores de 18 anos que aceitaram participar do presente estudo. Em seguida, baseando-se na metodologia de trabalho elaborada por Silva e Bastos (2012), foi realizada uma pesquisa descritiva a partir de observações feitas em sala de aula e aplicação de questionários estruturados (anexo 2) aos docentes e discentes. Para o desenvolvimento desta pesquisa, analisaram-se quatro turmas do sétimo ano, uma em cada escola de ensino fundamental da sede do município, sendo esta escolha baseada no fato de que os conteúdos referentes à Microbiologia são abordados nesta série.

A finalidade de utilização dos questionários foi verificar o nível de compreensão dos alunos e professores a respeito dos assuntos relacionados à Microbiologia, bem como apontar as principais dificuldades encontradas pelos docentes, para trabalhar os conteúdos relacionados a esta disciplina em sala de aula. Para os professores, as perguntas foram divididas em dois blocos: 
dados profissionais e ensino de Microbiologia. No primeiro foram respondidas perguntas sobre a formação profissional e o tempo de docência; no segundo eles responderam perguntas referentes ao ensino de Microbiologia na sala de aula. O questionário aplicado aos alunos teve como objetivo identificar o conhecimento que eles possuem acerca do tema. Os dados coletados por meio dos questionários foram tabulados e organizados sistematicamente, de maneira a possibilitar uma melhor análise dos mesmos.

\section{RESULTADOS E DISCUSSÕES}

\subsection{O Ensino de Microbiologia: Percepção dos Do- centes}

Foram entrevistados quatro professores de Ciências que trabalham nas quatro escolas públicas que abrangem a rede municipal de ensino da zona urbana da cidade de Jaguaribe-CE. Todos eles são graduados, sendo que apenas dois deles possuem algum tipo de especialização (Tabela 1). Em relação ao tempo de docência, três deles já possuem 10 anos ou mais de experiência.

Em relação às fontes de pesquisa utilizadas para o preparo das aulas de Microbiologia três professores (75\%) afirmaram utilizar livros, internet e artigos na preparação de suas aulas, enquanto que um (25\%) utiliza somente livros e internet. Quanto aos métodos e recursos utilizados pelos professores em suas aulas, três afirmaram utilizar aulas práticas, e somente um professor disse nunca ter realizado. De acordo com Barbosa e Barbosa (2010), as atividades práticas em Microbiologia são muito importantes para o desenvolvimento do aluno. Nos últimos anos, o melhoramento de técnicas e equipamentos laboratoriais na área da Microbiologia e Biotecnologia fez com que aumentasse o valor dos materiais utilizados nas práticas. A partir daí, houve maior dificuldade em se adquirir materiais pelas instituições de ensino assim como a manutenção desses laboratórios, o que inviabilizou o aprendizado prático.

Ainda em relação a esse aspecto, os professores destacaram que os conteúdos abordados pela Microbiologia podem e devem ser trabalhados com a utilização de materiais alternativos como jogos lúdicos, seminários e feira de ciências (PECHULA; POZZO; BOCANEGRA, 2012; SANTOS, 2012). Essa constatação confirma o que Barbosa e Barbosa (2010) sugerem em relação à utilização dos recursos didáticos nas aulas de Microbiologia

[...] faz-se necessário à utilização de meios e materiais alternativos na elaboração e realização de aulas práticas laboratoriais de Microbiologia refletindo aspectos teóricos

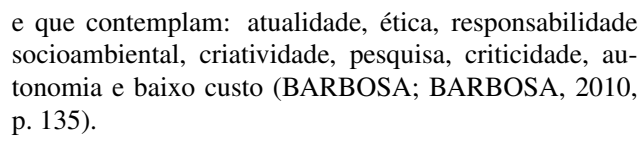

e que contemplam: atualidade, ética, responsabilidade socioambiental, criatividade, pesquisa, criticidade, autonomia e baixo custo BARBOSA; BARBOSA 2010. p. 135).

Na questão referente à contextualização e aproximação dos temas apresentados em sala de aula com os conhecimentos prévios dos alunos e a relação desses assuntos com o ambiente do educando, $100 \%$ dos professores afirmaram que pedem para seus alunos observarem o ambiente a sua volta, por exemplo, para que possam identificar a presença dos micro-organismos. Os professores ressaltaram ainda, que esclarecem para seus alunos a utilidade e os riscos que os micro-organismos podem trazer.

Por fim, quando foi perguntado aos professores se o Ensino de Ciências em suas escolas necessitava de mudanças, todos afirmaram que sim, evidenciando a percepção positiva dos professores quanto à necessidade de atualização no processo de ensino. Complementando essa informação os professores ressaltaram alguns pontos que contribuiriam para o aperfeiçoamento do Ensino de Ciências: a melhoria da estrutura das escolas e dos laboratórios, a formação continuada de professores, melhores livros, mais disponibilidade por parte da escola de materiais e tempo, experimentação e contextualização e maior frequência de aulas práticas.

\subsection{O Ensino de Microbiologia: Percepção dos Dis- centes}

Também participaram desse estudo 93 alunos do $7^{\circ}$ ano do ensino fundamental. A escolha do sétimo ano deveu-se ao fato de os conteúdos referentes aos temas de Microbiologia serem abordadas neste ano escolar. Inicialmente foi perguntado aos discentes o que eles mais gostavam de estudar nas aulas de Ciências. A pesquisa apontou que a maioria dos alunos, aproximadamente $55 \%$, gosta de estudar conteúdos relacionados com as plantas e os seres humanos (Figura 1), enquanto que $38 \%$ dos entrevistados salientaram gostar de estudar temas associados aos micro-organismos (vírus, bactérias e fungos).

Mesmo sendo as condições de trabalho observadas nas escolas desfavoráveis ao desempenho dessas atividades os temas relacionados à Microbiologia foram expressivamente citados, apesar de não terem sido a maioria, resultado que corrobora com os de Silva e Bastos (2012), que sugerem que os alunos possuem interesse por assuntos relacionados à Microbiologia.

Em relação à realização de aulas práticas, $58 \%$ dos discentes afirmaram não terem tido aula prática de Ciências. De acordo com a análise das respostas ante- 
Tabela 1: Formação dos docentes de Ciências do $7^{\circ}$ ano das escolas públicas da zona urbana da cidade de Jaguaribe-CE

\begin{tabular}{cc}
\hline FORMAÇÃO DOS DOCENTES EM CIÊNCIAS & NÚMERO DE DOCENTES \\
\hline Biologia e Química & 2 \\
Licenciatura em Ciências Biológicas & 1 \\
Biologia (Habilitação em regime especial) & 1 \\
\hline
\end{tabular}

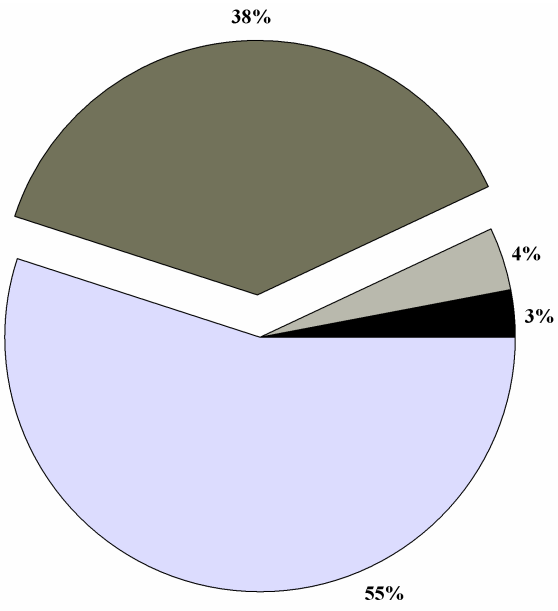

Não respondera

Gosta de tud

Conteúdos variados relacionados com as plantas

Figura 1: Principais temas que os alunos do $7^{\circ}$ ano das escolas públicas da zona urbana da cidade de Jaguaribe-CE gostam de estudar em Ciências.

Fonte: Próprios Autores.

riores e observações realizadas na sala de aula, pôdese perceber o interesse dos alunos acerca da realização de aulas de Microbiologia mais atrativas. Entretanto as dificuldades encontradas nas escolas públicas como a carência de recursos para construção ou adaptação de laboratórios e a falta de materiais para realização das práticas, são fatores que entravam sua execução.

Ao se avaliar a questão o que é a Microbiologia e o que essa disciplina estuda a maioria dos discentes, $74 \%$, relatou que não sabia o que era a Microbiologia e $66 \%$ afirmaram não saber o que era estudado por essa disciplina. Dos $31 \%$ que marcaram que sabia o que a Microbiologia estudava somente $7 \%$ responderam corretamente e $17 \%$ escreveram respostas que relacionavam os micro-organismos com plantas, insetos e/ou protozoários, um dos entrevistados respondeu ainda que a Microbiologia era uma doença. Isso retrata o que foi observado em sala de aula, já que boa parte dos professores não realizam uma introdução completa sobre o que é e o que estuda a Microbiologia.

$\mathrm{Na}$ questão que perguntava sobre qual é a impor- tância dos micro-organismos na natureza, 33\% dos alunos marcaram que eles são responsáveis pela produção de medicamentos, $13 \%$ destacaram que os microorganismos causam apenas doenças, $18 \%$ que eles participam da cadeia alimentar, $13 \%$ que eles são utilizados na produção de alimentos e $23 \%$ assinalaram que não sabem sobre essa importância (Figura 2).

Ao analisar essa questão podemos perceber que somente $13 \%$ deles assinalaram que os micro-organismos somente causam doenças, enquanto que a maioria $64 \%$ destacaram a importância benéfica desses organismos na natureza, associando-os a produção de alimentos e medicamentos e por participarem da cadeia alimentar (Figura 2). Isso nos leva a sugerir que eles possuem boa compreensão do papel dos micro-organismos em Microbiologia.

Entretanto, tal sugestão é questionável quando observamos as respostas dadas à pergunta que trata do papel dos fungos e bactérias na cadeia alimentar (Figura 3. Assim, $51 \%$ dos alunos apontaram que os fungos e as bactérias atuam como decompositores na cadeia alimentar. Já $42 \%$ dos entrevistados marcaram que esses dois grupos de micro-organismos prejudicam a cadeia alimentar. Resultados semelhantes aos aqui encontrados foram observados por Silva e Bastos (2012). Para esses autores, essas respostas indicam que os alunos associam os micro-organismos com malefícios a cadeia alimentar, provavelmente fazendo um paralelo com a visão de que os micro-organismos são causadores de doenças (SILVA; BASTOS, 2012).

$\mathrm{O}$ item que perguntava sobre os locais em que os micro-organismos estão presentes mostrou que 55\% dos alunos afirmaram que os micro-organismos estão presentes em todos os locais (Figura 4). Contudo, 30\% dos entrevistados atestaram que os micro-organismos estão no lixo e em locais como o chão, o nosso corpo e nossa casa, o que demostra que ainda há pouco esclarecimento sobre onde podemos encontrá-los. Corroborando o presente estudo alguns autores apontam que os alunos não estão sendo estimulados a um pensamento reflexivo de seu cotidiano com o conteúdo escolar, e dessa maneira, interpretam separadamente situações extremamente relacionadas (SILVA; BASTOS, 2012, REGINALDO; SHEID; GÜLLICH, 2012). 


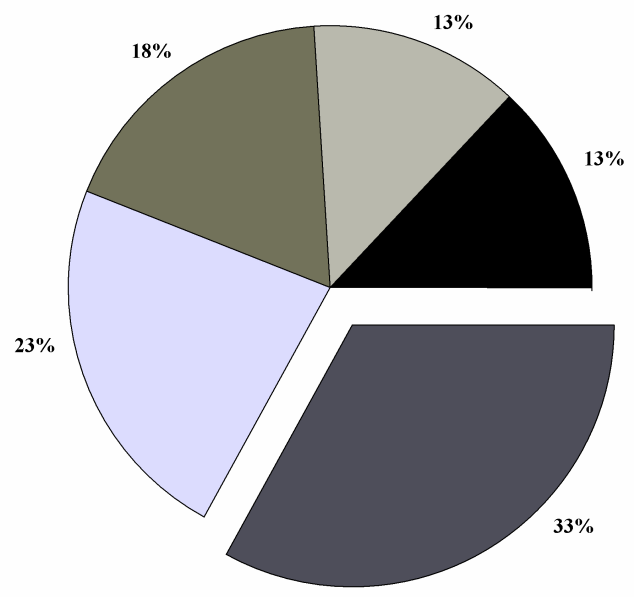

Somente causam doenças

São utilizados para a produção de alimentos Participam da cadeia alimenter

Não sei

São utilizados

Figura 2: Percepção dos alunos do $7^{\circ}$ ano das escolas públicas da zona urbana da cidade de Jaguaribe-CE em relação à importância dos micro-organismos na natureza.

Fonte: Próprios Autores.

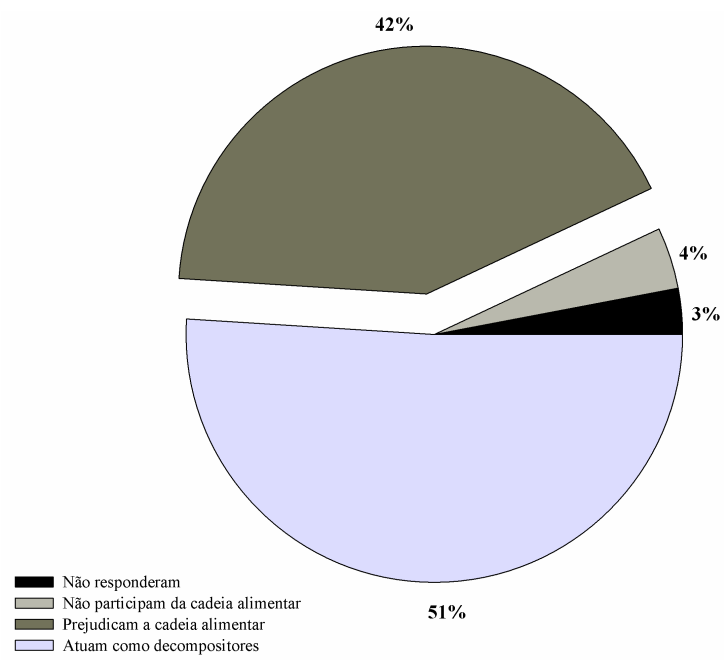

Figura 3: Percepção dos alunos do $7^{\circ}$ ano das escolas públicas da zona urbana da cidade de Jaguaribe-CE em relação ao papel desempenhado pelos fungos e bactérias na cadeia alimentar. Fonte: Próprios Autores.

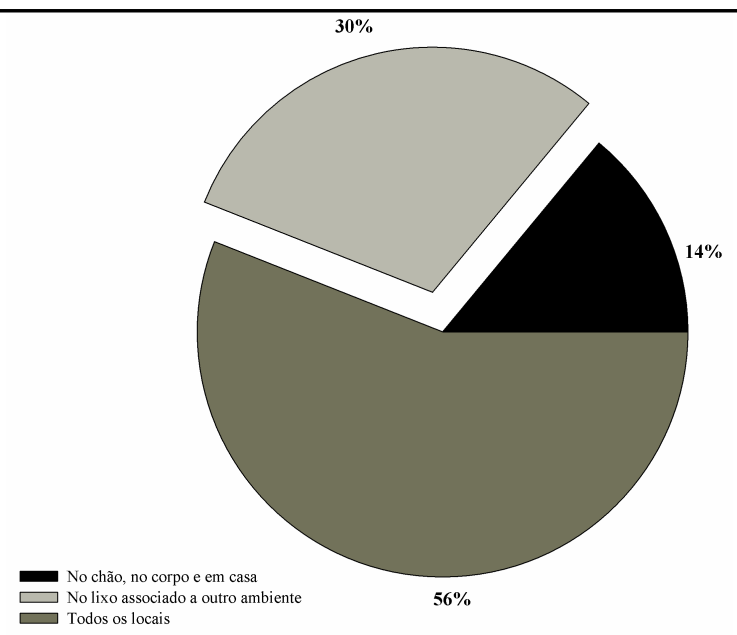

Figura 4: Percepção dos alunos do $7^{\circ}$ ano das escolas públicas da zona urbana da cidade de Jaguaribe-CE em relação aos locais em que os micro-organismos são encontrados.

Fonte: Próprios Autores.

Quando foi perguntado aos alunos sobre como eles achavam que as aulas de Ciências deveriam ser realizadas (Figura 5), encontramos entre a maioria dos alunos uma vontade de que as aulas de Ciências fossem mais lúdicas (17\%), com a realização de mais atividades experimentais $(16 \%)$, com mais atividade/trabalhos $(8 \%)$ e que fossem realizadas no laboratório (8\%). Já $5 \%$ dos alunos participante da pesquisa assinalaram que as aulas de Ciências não precisavam mudar em nada. Isso reflete a observação realizada em sala de aula, onde alguns dos professores que participaram da pesquisa utilizaram somente o livro didático como ferramenta de ensino, explorando apenas a leitura do assunto, sendo essa leitura feita na maioria das vezes pelo aluno. Dessa maneira, a ausência da apresentação de figuras e analogias e/ou comparações com o dia a dia do discente pode contribuir para que os conceitos apresentados em Microbiologia sejam de mais difícil compreensão.

Para Reginaldo, Sheid e Güllich (2012) no Ensino de Ciências, podemos destacar a dificuldade do aluno em relacionar a teoria desenvolvida em sala com a realidade a sua volta. A introdução de atividades práticas é fundamental para auxiliar no entendimento do conteúdo pelos alunos. As atividades práticas em Microbiologia são primordiais para o progresso do aluno, para tanto, é necessário à utilização de materiais e métodos alternativos na criação e execução de aulas práticas no laboratório de Microbiologia (Ciências) a fim de fixar a teoria vista em sala (BARBOSA; BARBOSA, 2010; SILVA; SOUZA, 2013). "A realização de experimentos, em Ci- 


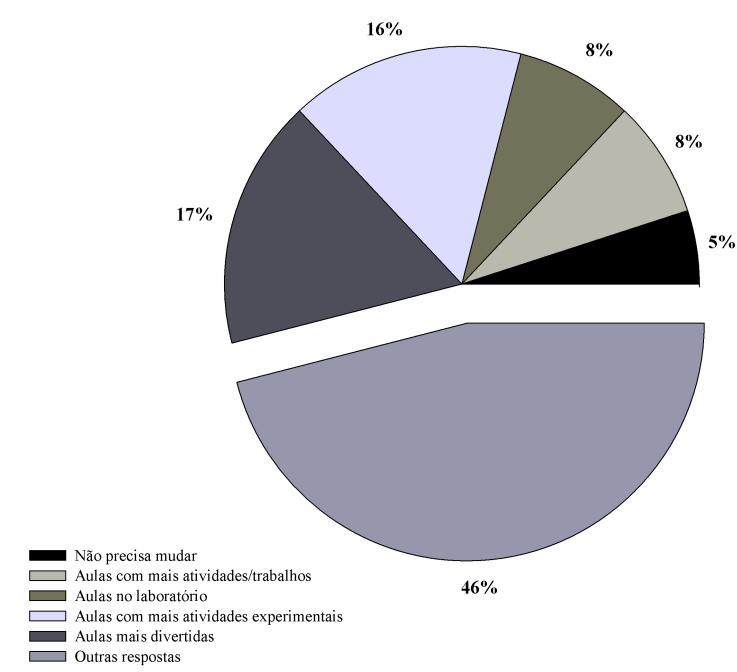

Figura 5: Percepção dos alunos do $7^{\circ}$ ano das escolas públicas da zona urbana da cidade de Jaguaribe-CE sobre como as aulas de Ciências deveriam ser realizadas.

Fonte: Próprios Autores.

ências, representa uma excelente ferramenta para que o aluno faça a experimentação do conteúdo e possa estabelecer a dinâmica e indissociável relação entre teoria e prática." (REGINALDO; SHEID; GÜLLICH, 2012. p. 2).

A última pergunta solicitava que os alunos apontassem qual era a maior dificuldade que eles encontram nas aulas de Ciências (Figura 6).

A maioria $(19 \%)$ citou que a maior dificuldade era compreender conceitos relacionados aos diferentes tipos de micro-organismos (vírus, fungos e bactérias). Em contrapartida, $17 \%$ dos alunos assinalaram não possuírem dificuldade alguma em relação às aulas de Ciências, enquanto $15 \%$ apontaram ter dificuldade na hora de resolver os exercícios e $11 \%$ destacaram que a dificuldade estava associada à utilização de palavras/termos difíceis nas aulas de Ciências.

Essa dificuldade pode ser constatada pelas observações feitas em sala de aula, onde somente dois dos professores participantes desse estudo apresentaram os micro-organismos em sala, seja através de figuras ou trazendo algum micro-organismo (exemplo: bolor no pão ou na laranja) para sala de aula. A transmissão do conteúdo não deve se dá somente através da leitura. Ademais, muitas dessas possibilidades estão distantes da realidade dos professores. "A superação de algumas das limitações depende de políticas públicas voltadas para a educação, com o intuito de suprir tais demandas e promover possibilidades de um processo de

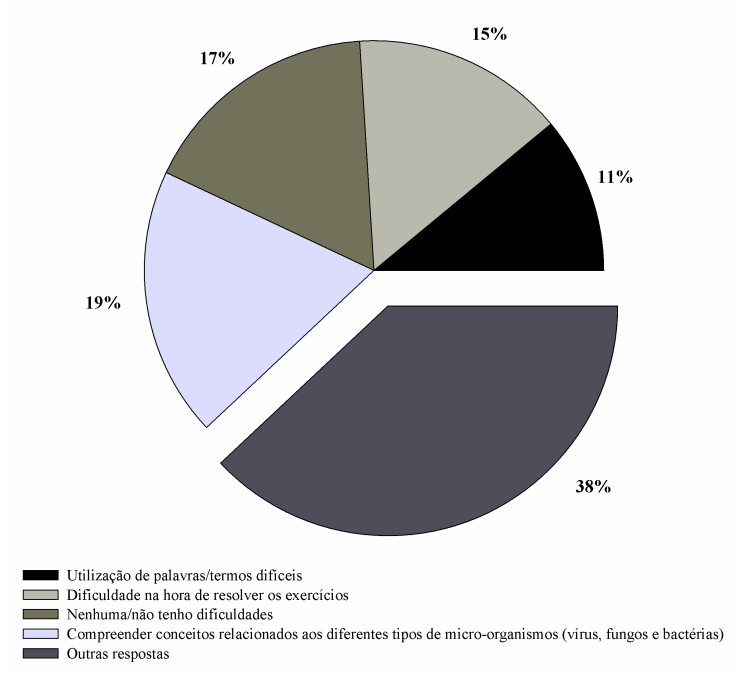

Figura 6: Dificuldades apontadas pelos alunos do $7^{\circ}$ ano das escolas públicas da zona urbana da cidade de Jaguaribe-CE em relação à aprendizagem nas aulas de Ciências.

Fonte: Próprios Autores.

ensino-aprendizagem eficiente e de qualidade na escola básica." (DOMINGUINI et al., 2012, p. 142).

\subsection{O Ensino de Microbiologia: o Livro Didático}

A análise das respostas dos professores acerca da utilização do livro didático revelou que para $100 \%$ dos entrevistados o livro didático serve como base para a preparação e o desenvolvimento das aulas:

"Para servir de base de pesquisa para os alunos bem como realização de algumas atividades sala/casa”.

"Leitura, atividade escrita e interpretação de figuras”.

"Como base para as aulas, mas sempre procuro acrescentar algo e fazer uma contextualização”.

"Utilizo frequentemente, uso as atividades necessárias”.

O livro didático deve servir como suporte para discussões em sala de aula, não só como fonte de informações, e o professor será a ferramenta para poder ensinar como utilizá-lo da melhor forma. Os alunos devem aprender a identificar os conceitos apresentados, e interpretá-los a sua maneira; aprender a compreender tabelas e gráficos, consultar índices remissivos e glossários. O professor deve buscar fazer comparações e 
analogias para auxiliar na compreensão e incentivar os alunos para a construção de resumos (KRASILCHIK, 2011). "O problema da linguagem na sala de aula envolve a capacidade dos alunos de formar conceitos e de pensar. A leitura de textos deve familiarizá-los com as estruturas linguísticas e com os estilos de apresentação típicos da biologia..." (KRASILCHIK, 2011, p. 70).

Resultados semelhantes aos aqui encontrados foram observados por Silva e Bastos (2012), confirmando a urgência de mudança nas metodologias de ensino utilizadas para o ensino de Microbiologia. Uma dessas modificações pode ser visto no estudo de Cassanti et al. (2008), que sugerem a realização de experimentos de Microbiologia com a utilização de materiais de baixo custo, como a criação de jogos didáticos e a elaboração de meios de cultura alternativos aos vendidos comercialmente. Outro exemplo baseia-se no trabalho de Barbosa e Barbosa (2010), que utilizaram/adaptaram a panela de pressão como autoclave.

\section{CONSIDERAÇÕES FINAIS}

A Microbiologia é uma disciplina muito favorável para o desenvolvimento de boas estratégias de ensinoaprendizagem em sala de aula, devido a sua proximidade com o cotidiano do discente. Dessa maneira, ações de debates, questionamentos, demonstrações e experiências devem ser incentivadas constantemente em sala de aula. Contudo, faz-se necessário salientar que o professor sozinho não pode desenvolver todas as atividades, sendo o apoio e a participação da gestão escolar e do poder público fator fundamental nesse processo. No presente estudo, percebe-se que, embora a avaliação dos discentes e docentes acerca das aulas de Microbiologia seja satisfatória, existe por parte dos dois grupos pesquisados (discentes e docentes), a necessidade de melhorias no processo de ensino dos temas relacionados a essa disciplina, o que certamente fortalecerá a aprendizagem dos discentes, favorecendo assim, a formação de conceitos sólidos acerca dos temas ensinados em Microbiologia e a melhor interpretação/associação dos temas ensinados a situações do seu cotidiano. Nessa perspectiva, sugerimos o incentivo à formação continuada dos professores de Ciências, para que ele esteja mais bem preparado para planejar, ministrar e inovar suas aulas de Microbiologia, tornando-as assim, mais atrativas e instigantes. Isso possibilitará uma dinamização das aulas, fomentando nos alunos o desejo de atuarem, juntamente com o professor, como agentes na construção do conhecimento.

\section{REFERÊNCIAS}

ANTUNES, C. H.; PILEGGI, M.; PAZDA, A. K. Por que a visão científica da microbiologia não tem o mesmo foco na percepção da microbiologia no ensino médio. SIMPÓSIO NACIONAL DE ENSINO DE CIÊNCIA E TECNOLOGIA, v. 3, 2012.

BARBOSA, F. H. F.; BARBOSA, L. P. Jardim de L. Alternativas metodológicas em microbiologiaviabilizando atividades práticas. Revista de biologia e Ciências da Terra, Universidade Estadual da Paraíba, v. 10, n. 2, 2010.

BROOKS, G. F.; CARROLL, K. C.; BUTEL, J. S.; MORSE, S. A.; MIETZNER, T. A. Microbiologia Médica de Jawetz, Melnick \& Adelberg-26. [S.1.]: AMGH Editora, 2014.

CASSANTI, A. C.; CASSANTI, A. C.; ARAÚJO, E. d.; URSI, S. Microbiologia democrática: estratégias de ensino-aprendizagem e formação de professores. Enciclopédia Biosfera, v. 8, p. 1-23, 2008.

DOMINGUINI, L.; GIASSI, M. G.; MARTINS, M. da C.; GOULART, M. d. L. M. Limites e possibilidades para trabalhar com o ensino de ciências em escolas da rede pública de um muníicipio do sul de santa catarina. In: Simpósio Nacional de Ensino de Ciência e Tecnologia. Ponto Grossa: Anais, 2012. Disponível em: $<$ http://www.sinect.com.br/anais2012/html/index.html >. Acesso em: 10 ago. 2016.

IPECE. Ceará em mapas. 2007. Disponível em: <http: //www2.ipece.ce.gov.br/atlas/capitulo1/12/index.htm>. Acesso em: 20 Set. 2016.

KIMURA, A. H.; OLIVEIRA, G. S. de; SCANDORIEIRO, S.; SOUZA, P. C. de; SCHURUFF, P. A.; MEDEIROS, L. P.; BODMAR, C. G.; SARMIENTO, J. J. P.; GAZAL, L. E. de S.; SANTOS, P. M. C. dos et al. Microbiologia para o ensino médio e técnico: contribuição da extensão ao ensino e aplicação da ciência. Revista Conexão UEPG, v. 9, n. 2, p. 254-267, 2013.

KRASILCHIK, M. Prática de ensino de biologia. São Paulo: Edusp, 2011.

MADIGAN, M. T.; MARTINKO, J. M.; BENDER, K. S.; BUCKLEY, D. H.; STAHL, D. A. Microbiologia de Brock-14ª Edição. [S.1.]: Artmed Editora, 2016. 
PECHULA, M. R.; POZZO, L. D.; BOCANEGRA, C. H. Considerações sobre o ensino de ciências e o uso de materiais didáticos midiáticos: Possibilidades e limites. Revista Contrapontos, v. 12, n. 2, p. 145-153, 2012.

REGINALDO, C. C.; SHEID, N. J.; GÜLLICH, R. I. d. C. O ensino de ciências e a experimentação. Anaped Sul: Seminário de Pesquisa em Educação da Região Sul, Giruá, p. 1-13, 2012.

SANTOS, A. d. S. Prática investigativa: experimentando o mundo da microbiologia. Seminário Nacional do Ensino Médio: profissão docente, currículo e novas tecnologias, 2012. Rio Grande do Norte.

SANTOS, W. L. P. d. Educação científica na perspectiva de letramento como prática social: funções, princípios e desafios. Revista Brasileira de Educação, SciELO Brasil, v. 12, n. 1, p. 473-550, 2007.

SILVA, E. R. S.; SOUZA, A. S. Introdução ao Estudo da Microbiologia: teoria e prática. [S.1.]: EDITORA IFB, 2013.

SILVA, M. . S. d.; BASTOS, S. N. D. Ensino de microbiologia: Percepção de docentes de discentes nas escolas públicas de mosqueiro, belém, pará. III Encontro Nacional de Ensino de Ciências, Saúde e Meio Ambiente-UFFNiterói, 2012.

SPOLIDORIO, D.; DUQUE, C. Microbiologia e imunologia geral e odontológica. Vol. 1. [S.1.]: São Paulo: Artes Médicas, 2013.

TORTORA, G. J.; FUNKE, B. R.; CASE, C. L. Microbiologia. Porto Alegre: Artmed, 2017. 

CEARÁ

A Termo de Consentimento Livre e Esclarecido

\author{
INSTITUTO FEDERAL | \\ Instituto Federal de Educação, Ciência e Tecnologia do Ceará \\ Campus Jaguaribe \\ Licenciatura em Ciências Biológicas
}

Termo de Consentimento Livre e Esclarecido

Prezado(a) Senhor(a)

Gostaríamos de convidar o menor sob sua responsabilidade a participar de nosso estudo "O ENSINO DE MICROBIOLOGIA NAS ESCOLAS PÚBLICAS DE ENSINO FUNDAMENTAL DO MUNICÍPIO DE JAGUARIBE, CEARÁ." A fim de sugerir metodologias que facilitem as aulas sobre o tema. A pesquisa consistirá na observação das aulas e aplicação de questionários para professores e alunos relacionados ao tema, e posterior análise dos dados.

Trata-se de um Trabalho de Conclusão de Curso (TCC), desenvolvido por Chayenne Alves de Sá e orientado pela Prof. ${ }^{2}$ Dra. Valdineia Soares Freitas, do curso de Licenciatura em Ciências Biológicas do Instituto Federal de Educação, Ciência e Tecnologia do Ceará (IFCE) - Campus Jaguaribe.

A qualquer momento da realização desse estudo, os participantes receberão esclarecimentos adicionais que julgarem necessários, bem como poderão recusar-se a participar ou retirar-se da pesquisa, sem nenhum tipo de penalidade, constrangimento ou prejuizo. O sigilo das informações será preservado, especificamente, nenhum nome, identificação de pessoas ou de locais interessa a esse estudo. Todos os registros efetuados no decorrer desta investigação serão usados para fins unicamente acadêmico-científicos e apresentados na forma de TCC, monografia e/ou artigo científico, não sendo utilizados para fim comercial.

Em caso de concordância com as considerações expostas, solicitamos que assine este "Termo de Consentimento Livre e Esclarecido" no local indicado abaixo. Desde já agradecemos sua colaboração e nos comprometemos com a disponibilização à instituição dos resultados obtidos nesta pesquisa, tornando-os acessiveis a todos os participantes.

\footnotetext{
Pesquisadora

Licenciatura em Ciências Biológicas

IFCE - Campus Jaguaribe
}

\author{
Orientadora \\ IFCE - Campus Jaguaribe
}


$\mathrm{Eu}$ assino 0

termo de consentimento, após esclarecimento e concordância com os objetivos e condições da realização da pesquisa "O ENSINO DE MICROBIOLOGIA NAS ESCOLAS PÚBLICAS DE ENSINO FUNDAMENTAL DO MUNICÍPIO DE JAGUARIBE, CEARÁ.", permitindo que o(a) menor sob minha responsabilidade

pesquisa acima mencionada. participe da

Jaguaribe - Ceará de 2015

Assinatura do(a) Pesquisado(a)/Responsável

Qualquer dúvida ou maiores esclarecimentos entrem em contato com os responsáveis pelo estudo:

e-mail: chayennebio@gmail.com / valdineiasoares@ifce.edu.br 


\section{B Questionários estruturados}

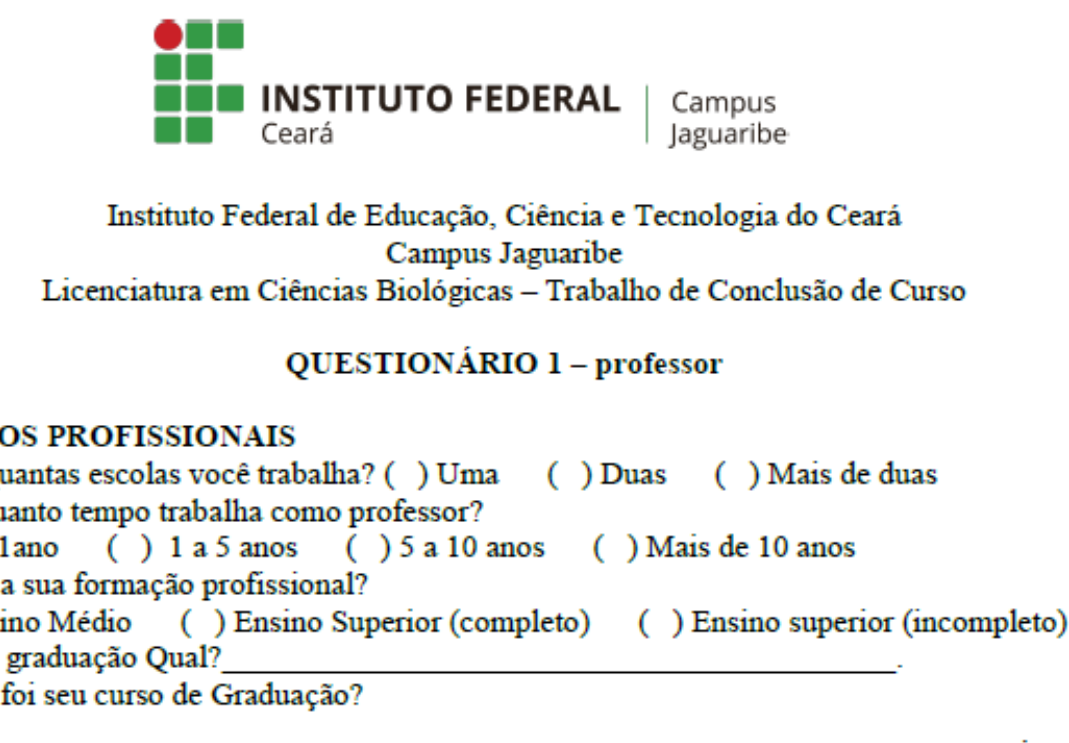

\section{ENSINO DE MICROBIOLOGIA}

1. Você costuma contextualizar o tema da aula, perguntando aos alunos o que eles já sabem acerca do assunto de Microbiologia antes de iniciar sua exposição?

( ) $\operatorname{sim}($ ) não ( ) não lembro ( ) não vejo necessidade

2. Quais fontes você utiliza para preparar as aulas de Microbiologia? (pode marcar mais de uma)
( ) livros
( ) artigos
( ) internet
( ) todos
( ) nenhuma, já sei de tudo sobre o
conteúdo
( ) outras

Quais?

3. Você utiliza aulas práticas em Microbiologia com qual frequência? Em caso afirmativo, cite-as. ( ) algumas aulas ( ) todas as aulas ( ) nunca usei

4. Você pede aos seus alunos para que observem os ambientes a sua volta, identificando os micro-organismos? ( ) $\operatorname{sim}$ ( ) não ( ) não lembro

5. Você esclarece seus alunos acerca da utilidade que os micro-organismos representam para a humanidade? Em caso afirmativo, cite-as. ( ) sim ( ) não ( ) não lembro

6. Você esclarece seus alunos acerca dos riscos que os micro-organismos representam para a humanidade? Em caso afirmativo, cite-os. ( ) sim ( ) não ( ) não lembro

7. Você acha possivel trabalhar os assuntos relacionados à Microbiologia com materiais alternativos como: ( ) jogos lúdicos ( ) seminários ( ) feiras de ciências ( ) todos ( ) não dá, só falando ( ) Nunca pensei sobre isso

8. Quais são as suas principais dificuldades em ministrar Microbiologia nas escolas?

( ) falta de materiais (quadro branco ou de giz, cartolinas, laboratórios de ciências, data show, etc.) ( ) desinteresse dos alunos ( ) desinteresse da escola ( ) desinteresse pessoal ( ) todos ( ) nenhuma ()outros: 
Quais?

9. Como você utiliza o livro didático?

10. Você faz atualização dos planos de aula ao passar dos anos?

() $\operatorname{sim}()$ não () nem sempre.

11. Para você, o Ensino de Ciências necessita de mudanças? Cite-as. 


\section{INSTITUTO FEDERAL | \\ Instituto Federal de Educação, Ciência e Tecnologia do Ceará \\ Campus Jaguaribe \\ Licenciatura em Ciências Biológicas - Trabalho de Conclusão de Curso \\ QUESTIONÁRIO 2 - ALUNO}

\section{ENSINO DE CIÊNCIAS}

1. Qual foi conteúdo de Ciências que você mais gostou?
( ) ecologia
( ) micro-organismos
( ) nenhum
( ) outro

Qual?

3. Você costuma ter aulas práticas de Ciências? ( ) sim ( ) não ( ) não lembro

Em caso afirmativo, qual a frequência ( ) uma ( ) várias ( ) nenhuma

\section{CONTEÚDO DE MICROBIOLOGIA}

1. Você sabe o que é Microbiologia? Em caso afirmativo, defina. ( ) sim ( ) não

2. Você sabe o que estudamos em Microbiologia? Em caso afirmativo, liste-os.

( ) $\operatorname{sim}$ ( ) não

3. Na lista de organismos abaixo, assinale os micro-organismos estudados na Microbiologia:
( ) fungos
( ) ameba
( ) bactérias
( ) virus
( ) protozoários
( ) insetos

4. Assinale as alternativas que mostram qual a importância dos micro-organismos na natureza:

( ) só causam doenças ( ) são utilizados para produção de medicamentos

( ) são utilizados na produção de alimentos ( ) participam da cadeia alimentar

( ) não sei

5. Qual é o papel dos fungos e bactérias na cadeia alimentar?

$\begin{array}{ll}\text { ( ) prejudicam a cadeia alimentar ( ) atuam como decompositores } & \text { ( ) }\end{array}$

( ) não estão na cadeia alimentar

6. Em que local os micro-organismo estão presentes? (pode marcar mais de um)
( ) no lixo
( ) no chão
( ) no nosso corpo ( ) em casa
( ) todos
8. Como você acha que as aulas de Ciências deveriam ser?

9. Qual a dificuldade que você encontra nas aulas de Ciências? 